\title{
Estimation of Above Ground Tree Biomass and Carbon of Pinus caribaea (Morelet)
}

\author{
S.M.C.U.P. Subasinghe*, G.B. Munasinghe \\ Department of Forestry and Environmental Science University of Sri Jayewardenepura \\ Nugegoda, Sri Lanka
}

Date Received: 09-05-2011 Date Accepted: 02-10-2011

\begin{abstract}
Forests in Sri Lanka contribute to the mitigation of global climate change through sequestrating a net amount of carbon dioxide and also maintaining carbon stocks as forest biomass. This study was conducted using an empirical method to understand the biomass and stored carbon by forest plantations in Sri Lanka. Further, in this study, the possibility of predicting the above ground tree biomass and carbon of Pinus caribaea (Morelet) was investigated. A 27 year old P. caribaea plantation was selected from the Low Country Wet Zone in Sri Lanka and the data were collected using 0.05 ha sample plots. Without felling trees, a core sample was obtained from the stem and biomass and carbon of that sample was used to estimate the stem biomass and carbon through volume measurements. The canopy biomass and carbon were estimated using samples of primary, secondary and tertiary branches and leaves. The total above ground tree biomass and carbon were estimated by adding the stem and canopy values together.

It was found that, for 27 year old P. caribaea, the average above ground tree biomass was $368.9 \mathrm{~kg}$ and the carbon was $215.9 \mathrm{~kg}$ which is $58.5 \%$ from the biomass. The amount of carbon in the canopy was $64.5 \%$ from the canopy dry mass. The carbon percentages of the primary, secondary and tertiary branches and leaves were $61.7,59.1$ and 79.6 respectively. The total above ground tree carbon for a 27 year old P. caribaea plantation was $103.6 \mathrm{~T} \mathrm{ha}^{-1}$.

Then regression models were developed to identify the relationships of biomass and carbon with stem volume. A relationship between biomass and carbon was also developed for the selected species. Finally, mathematical models were developed to predict biomass and carbon using some other tree variables such as diameter and height, without felling the trees.
\end{abstract}

*Correspondence: E-mail upul.forestry@gmail.com

Tel: 0094112804685 Fax: 0094112802914

ISSN 2235-9370 Print/ ISSN 2235-9362 Online @2011 University of Sri Jayewardenepura 
Subasinghe \& Munasinghe /Journal of Tropical Forestry and Environment Vol. 01, No. 01 (2011) 56-70

\section{Introduction}

Atmospheric carbon dioxide $\left(\mathrm{CO}_{2}\right)$ has increased significantly in the recent decades, with the major contributing factor being the combustion of fossil fuels in the production of energy and the second factor being land use practices (e.g., deforestation) that reduce the stock of carbon held in forest and soils (Sedjo, et al., 1997, FAO, 2002). The greenhouse effect is the result of the increase in the atmospheric temperature caused by the rapid increase in the concentration of atmospheric carbon dioxide (William, 1995).

Atmospheric $\mathrm{CO}_{2}$ is directly linked to terrestrial ecosystems through the global carbon cycle. Green plants take up atmospheric $\mathrm{CO}_{2}$ and convert it to cellulose and other organic compounds. Many of these compounds such as wood and some soil organic compounds are relatively stable, and maintain the carbon in inert form for many years, until the carbon is once again released in gaseous form due to the biological respiration or combustion (Sedjo, et al., 1997).

The high rates of deforestation in the tropics, especially during 1980s, caused the overall negative carbon exchange between the forests and atmosphere. At the beginning of 1980s, the estimated accumulation of carbon in recovering tropical landscapes which had previously been disturbed was roughly equal to the net carbon emission due to tropical deforestation and associated burning (Lugo and Brown, 1992).

Green plants remove $\mathrm{CO}_{2}$ from the atmosphere through photosynthesis. The carbon is stored in the foliage, stems, and root systems. Due to the long lifespan of most of the trees and their relatively larger sizes, trees and forests act as storehouses of carbon (William, 1995). The world forests have been estimated to contain up to $80 \%$ of all above ground terrestrial carbon and approximately $40 \%$ of all below ground terrestrial carbon (soil, litter and roots). Approximately 37\% of this carbon is stored in low latitude (tropical) forests, $14 \%$ in mid latitude (temperate) forests and $49 \%$ in high latitude forests (Dixon, et al., 1994).

Forest plantations received considerable publicity, particularly in the Southern hemisphere, where high biomass increment rates can be received. A number of restrictions can be identified that limit the availability of suitable lands for afforestation, particularly when suggested for such a large-scale purpose (Kohlmaier, et al., 1998). Pinus caribaea is one of the commonest forest plantation species was introduced to Sri Lanka for the rapid rehabilitation of the deforested and degraded lands in the wet zone and the hilly areas in the intermediate zone. In the year 2000, Sri Lanka Forest Department maintained a 16,589.3 ha of Pinus caribaea and P. patula plantations (Gunathilake and Palamakumbura, 2001) which are approximately $0.25 \%$ of the total land area. Almost all the pine plantations were established in Sri Lanka within a short period of time in 1970s. Therefore, due to the mature age of those planted trees, it is important to know the amounts of carbon trapped in the stem and branches and to predict those values using some other easily measurable tree variables such as diameter and height. The objectives of this study were: (i) estimation of above ground volume, biomass and carbon amount for $P$. caribaea plantations; and (ii) construction of mathematical models to predict above ground tree carbon from various explanatory variables that are easily measurable. 


\section{Methodology}

Due to the recent interests regarding tree planting and maintenance as carbon sinks, this study was focused on a selected Pinus caribaea (Morelet) plantation in Sri Lanka in order to predict the stored carbon in above ground tree parts and to identify the relationship between other tree variables such as biomass and volume so that in future it would not be necessary to carry out destructive sampling biomass and carbon estimations.

\subsection{Study area}

For this study, a 27 year old even aged Pinus caribaea plantation was selected from the southern part of Sri Lanka. This 25 ha population is located between N 06020/ - 06o22/ to E 80o10/ - 80o12/ in Kalutara Administrative District in the low country wet zone. The annual rainfall in the area is over $4,000 \mathrm{~mm}$ and the average temperature is between $27-28.50 \mathrm{C}$.

\subsection{Sampling}

Being there were slight geographical variations in the selected forest, the entire even-aged plantation was divided into three strata i.e., valley, slope and ridge top and two 0.05 ha circular samples were randomly selected from each stratum for data collection.

\subsection{Measurements}

i. Volume estimation

Newton's formula (Philip, 1994; Subasinghe, 1998) was used to estimate the precise stem volumes for this study. Standing trees were divided into sections less than $3 \mathrm{~m}$ and base, top and mid diameters and length of each section were accurately measured. Then the volume for each section was separately estimated using Newton's formula. The top most section was assumed as a cone. In order to calculate the total stem volume, the section volumes were added together as shown in equation (1).

$$
v=\Sigma v_{s}+v_{f}
$$

where:

$v=$ total stem volume, $\mathrm{m}^{3}$

$v_{f}=$ volume of the final section (cone), $\mathrm{m}^{3}$

$v_{s}=$ volume of the $s^{\text {th }}$ section, $\mathrm{m}^{3}$

ii. Estimation of stem biomass and carbon

Early studies conducted for the same species indicated that the biomass per unit volume (wood density) is not significantly different along the stem from the bottom to the top (Haripriya, 2003). Therefore, it was decided to use only one core sample from the tree stem for the analysis of carbon and biomass. Those core samples were extracted at the breast height and green volume and oven dry weight were measured. Then they were oven-dried at $105^{\circ} \mathrm{C}$ until a constant weight was achieved. The dry weight of the entire main stem was then calculated using equation (2). 


$$
w_{s}=\frac{w_{c} \times v}{v_{c}}
$$

where: $v_{c}=$ green volume of the core sample, $\mathrm{m}^{3}$

$w_{c}=$ dry weight of the core sample, $\mathrm{kg}$

$$
w_{s}=\text { total dry mass of the stem, } \mathrm{kg}
$$

The available carbon was determined by using the Walkley and Black method for the dried samples and it was converted to the entire stem using equation (3).

$$
c_{s}=\frac{c_{c}}{v_{c}} \times v
$$

where: $c_{c}=\mathrm{C}$ amount of the core, $\mathrm{kg}$

$$
c_{s}=\mathrm{C} \text { amount of the stem, } \mathrm{kg}
$$

iii. Estimation of canopy biomass and carbon

The canopy of Pinus caribaea is conical in shape. First the total number of branches which formed the canopy was counted. Then the canopy was divided into three parts i.e., top, middle and bottom and one branch representing each section was selected as a sample. Each selected branch was separated into three parts as primary, secondary and tertiary. The dry mass of those samples were determined by placing them in an oven at $105^{\circ} \mathrm{C}$ until those achieved a constant weight.

First the values of three selected branches (top, mid and bottom) were added and averaged to estimate the total canopy biomass. Then that value was multiplied by number of branches in order to estimate the canopy biomass. Amount of $\mathrm{C}$ in primary, secondary, tertiary branches and leaves were estimated using equation (4) and using those values in equation (5), total carbon amount was estimated.

$$
\begin{aligned}
& C_{b, l}=\frac{x_{b, l}}{s_{b, l}} w_{b, l} \\
& C_{\text {canopy }}=C_{p b}+C_{s b}+C_{t b}+C_{l}
\end{aligned}
$$

where: $C_{\text {canopy }}=$ carbon amount in canopy, $\mathrm{kg}$

$C_{b, l}=\mathrm{C}$ amount in ${ }^{\mathrm{ry}}, \mathrm{II}^{\mathrm{ry}}, \mathrm{III}^{\mathrm{ry}}$ branches or leaves, $\mathrm{kg}$

$C_{l} \quad=$ leaf $\mathrm{C}$ amount, $\mathrm{kg}$

$C_{p b}=\mathrm{C}$ in primary branches, $\mathrm{kg}$

$C_{s b} \quad=$ C in secondary branches, $\mathrm{kg}$ 
$C_{t b}=\mathrm{C}$ in tertiary branches, $\mathrm{kg}$

$s_{b, l}=$ sample weight of $\mathrm{I}^{\mathrm{ry}}, \mathrm{II}^{\mathrm{ry}}, \mathrm{III}^{\mathrm{ry}}$ branches or leaves

$w_{b, l}=$ dry weight of $\mathrm{I}^{\mathrm{ry}}, \mathrm{II}^{\mathrm{ry}}, \mathrm{III}^{\mathrm{ry}}$ branches or leaves in the canopy, $\mathrm{kg}$

$x_{b, l}=\mathrm{C}$ in the sample of $\mathrm{I}^{\mathrm{ry}}, \mathrm{II}^{\mathrm{ry}}, \mathrm{III}^{\mathrm{ry}}$ branches or leaves in the canopy, $\mathrm{kg}$

iv. Total above ground carbon

Total above ground carbon per each tree was estimated by adding the stem carbon and canopy carbon values together.

v. Amount of above ground tree $\mathrm{C}$ in one hectare land of P. caribaea

After estimation of the above ground carbon amount for $P$ caribaea in each sample plot, the carbon amount stored in stems and canopies in a unit area (one hectare) of the forest was estimated using equation (6).

$$
\mathrm{C}=\frac{\Sigma C_{p l o t}}{n a}
$$

where: $a \quad=$ plot area, ha

$C \quad=$ Carbon stored in stems and canopies per ha, $\mathrm{kg}$

$C_{\text {plot }}=$ above ground tree carbon per plot

$n \quad=$ number of plots

vi. Establishment of relationships

In order to identify the relationship between above ground carbon and biomass of the selected species and to predict the available carbon using the tree variables that can be measured easily, regression analysis was performed as follows.

Stem carbon vs stem biomass

Stem carbon vs stem volume

Stem carbon vs diameter at breast height (dbh)

Stem carbon vs. dbh and total height

Above ground tree carbon vs. above ground tree biomass

Above ground tree carbon vs stem volume

Above ground tree carbon vs dbh

Validating of identified models were conducted by performing appropriate statistical tests and be investigating residuals.

60 
Subasinghe \& Munasinghe /Journal of Tropical Forestry and Environment Vol. 01, No. 01 (2011) 56-70

\section{Results}

\subsection{Biomass and carbon of the canopy}

Carbon compositions of the various parts of the canopy of 27 year old $P$. caribaea found to be different (Figure 1) depending on the size and the storage capacity.

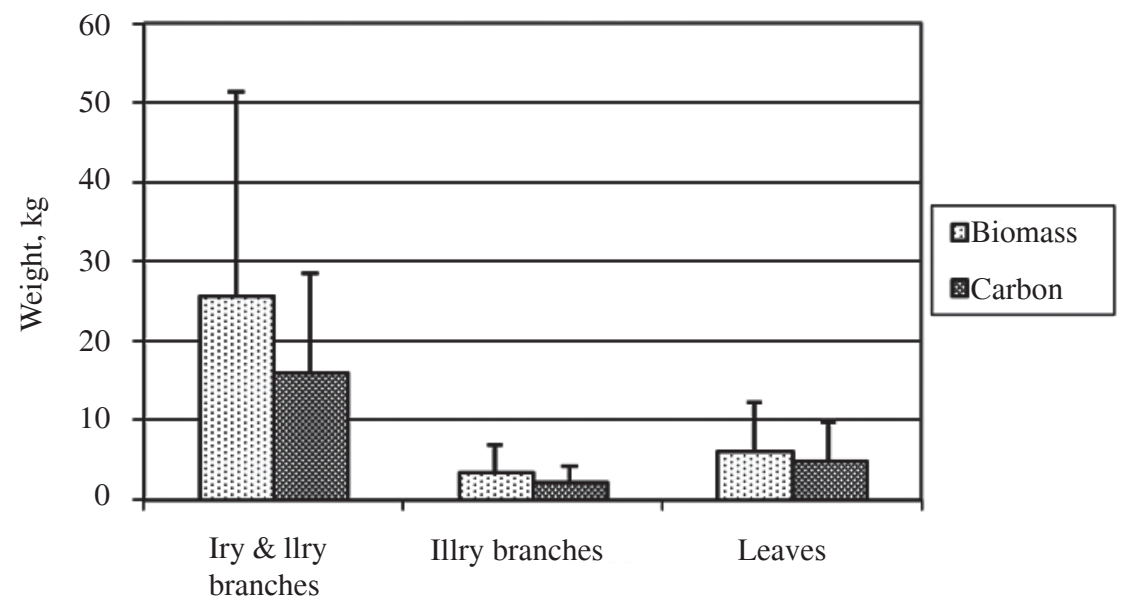

Figure 1: Estimated biomass and carbon values and mean confidence intervals of the various parts of tree canopy.

Biomass and carbon were the highest in primary and secondary branches in the canopy. The average total canopy biomass is $35.4 \mathrm{~kg}$ while the average canopy carbon is $22.9 \mathrm{~kg}$ which is $64.5 \%$. The carbon percentages of $\mathrm{I}^{\mathrm{ry}}$ and $\mathrm{II}^{\mathrm{ry}}$ branches and $\mathrm{III}^{\mathrm{ry}}$ branches and leaves are $61.7 \%, 59.1 \%$ and $79.6 \%$ respectively from biomass values (Figure 2). When 1-way ANOVA was performed, biomass of $\mathrm{I}^{\mathrm{ry}}$ and II $^{\mathrm{ry}}$ branches were significantly different from that of other two parts of the canopy $(\mathrm{F}$ value $=13.73$ and $\mathrm{p}$ value $=$ 0.000 at $95 \%$ probability level). Similar results were also observed for canopy carbon values ( $\mathrm{F}$ value $=$ 12.65 and $\mathrm{p}$ value $=0.000$ at $95 \%$ probability level).

\subsection{Biomass and carbon in the stem}

The average biomass per individual P. caribaea stem in the selected forest was $333.5 \mathrm{~kg}$ while the carbon amount wais $193.0 \mathrm{~kg}$ (Figure 3). Therefore the carbon content is $57.6 \%$ of the stem biomass (Figure 2).

\subsection{Above ground biomass and above ground carbon per tree}

Distribution of the amounts of above ground carbon and biomass for different tree parts are given in Figure 2. When compared with the mature tree stem of P. caribaea, biomass and carbon of the canopy become very low. The reason is that the conifers do not produce large crowns, and the number of leaves in the canopy is lower when compared to the most of broad-leaf species. 


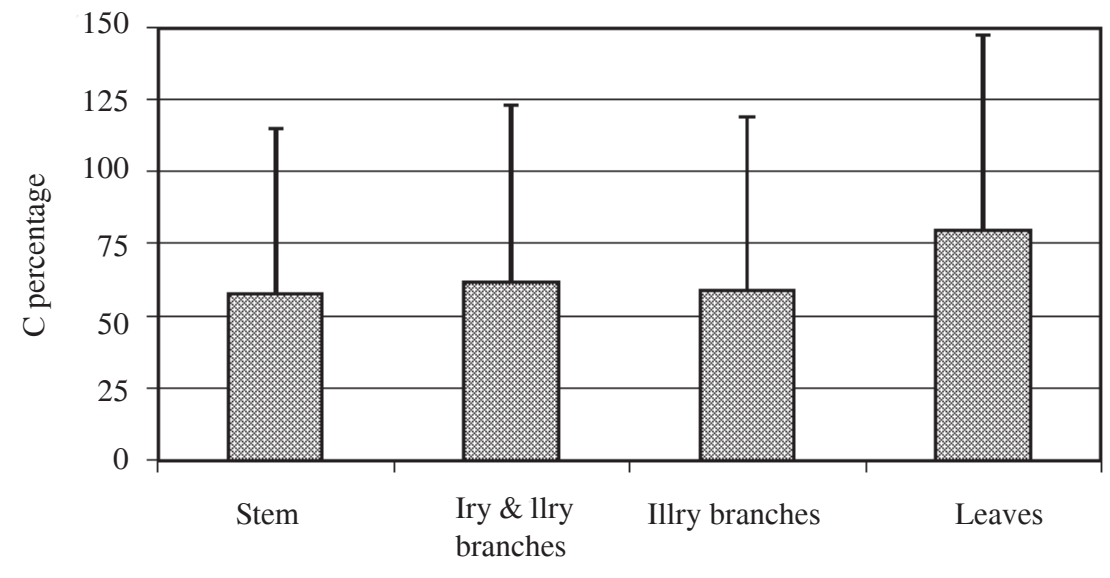

Figure 2: Carbon percentages from the respective biomass values and mean confidence intervals of different parts of $P$. caribaea.

The average total above ground biomass per tree of the selected species was $368.9 \mathrm{~kg}$ while the stored carbon amount was $215.9 \mathrm{~kg}$ (Figure 2) which is $58.5 \%$ from the dry mass. According to the twosample $t$ test, biomass and carbon values for stem and canopy indicated significant differences ( $t$ values $=4.11$ and 4.08 and $\mathrm{p}$ values $=0.003$ and 0.003 respectively for biomass and carbon).

Figure 3 illustrates carbon percentages with respect to biomass values of different parts of $P$. caribaea trees. 1-way ANOVA was performed for those values to identify the differences of carbon percentages ( $\mathrm{F}$ value $=83.39$ and $\mathrm{p}$ value $=0.000$ at $95 \%$ probability level $)$. However, according to the further analysis, it was proved that only leaf carbon percentage was significantly different from the carbon percentages in rest of the parts of the tree.

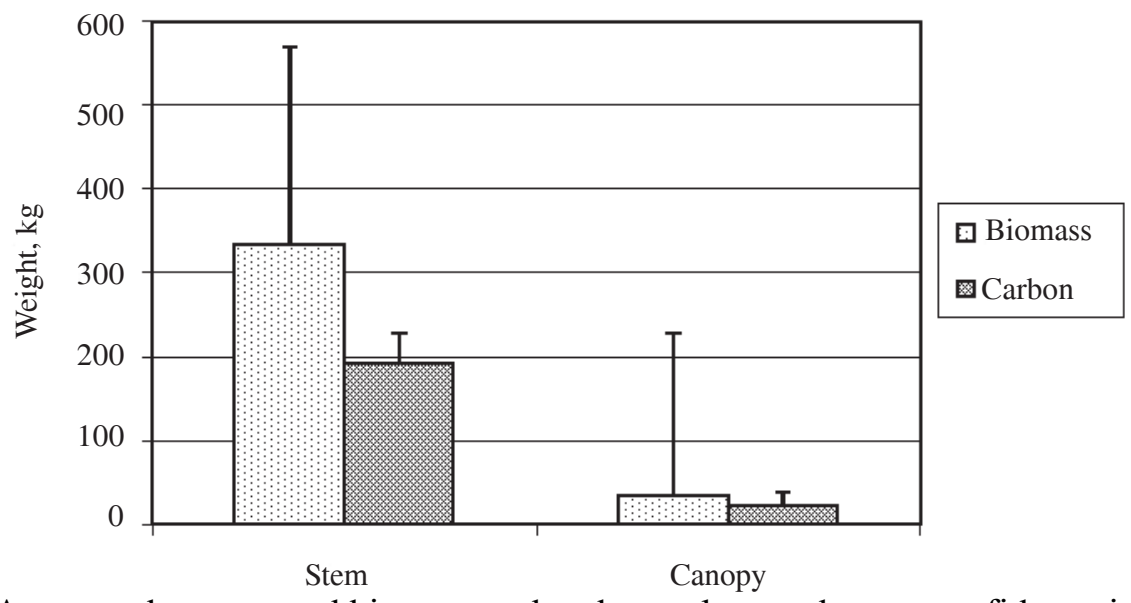

Figure 3: Average above ground biomass and carbon values and mean confidence intervals for $P$. caribaea 


\subsection{Amount of carbon content in Yagirala Pine Forest and in pine forests in Sri Lanka}

It was found that above ground carbon amount per tree is $215.9 \mathrm{~kg}$ for the selected species. According to the initial measurements, an average number of pine trees per hectare in the Yagirala Forest was 480 and therefore the amount of above ground $\mathrm{C}$ is $103.632 \mathrm{~T}$ ha-1. All pine plantations were established in Sri Lanka approximately at the same time and therefore it can be concluded that all the pine plantations are similar in age. If it is assumed that due to the application of the same treatments, the number of available trees per hectare is similar, the amount of above ground carbon available in all the pine plantations in Sri Lanka is 1,719,183.34 T, because the area covered by those pine plantations is $16,589.3$ ha (Bandaratillake, 2001).

\subsection{Relationship of above ground carbon with other tree variables}

Regression analyses was carried out to build the mathematical relationships of carbon with other selected variables. In order to find the best models, other than the original form, biologically acceptable transformations i.e., square, square root, logarithmic and reciprocal were also used for both response and explanatory variables.

\subsubsection{Stem carbon vs stem mass}

Initially five models were identified to observe the relationship between stem carbon and stem mass from twenty five possible combinations of equations. Out of those equations,

$\sqrt{C_{s}}=0.689+0.711 \sqrt{m_{s}}$ had the best relationship. Further analysis of this model proved that the intercept was not significant ( $\mathrm{p}$ value $=0.165$ ). Therefore it was removed from the model and re-fitted to obtain equation (7). $\mathrm{R}^{2}$ of model (7) was $95.0 \%$ (Figure 4).

$$
\sqrt{C_{s}}=0.755 \sqrt{m_{s}}
$$

where: $C_{s}=$ carbon trapped in the stem biomass, $\mathrm{kg}$

$$
m_{s}=\text { dry mass of the pine stem, } \mathrm{kg}
$$

\subsubsection{Stem carbon vs stem volume}

From stem carbon and stem volume, another twenty five relationships were initially developed. Among those models, the best model was $\sqrt{C_{s}}=0.081+17.7 \sqrt{v_{s}}$, which had a non-significant intercept ( $\mathrm{p}$ value $=0.897$ ). Moreover, when volume is 0 , carbon value should also be 0 as it cannot exist without a volume. Therefore equation (8) estimated by re-fitting the above model was selected as the best relationship (Figure 5) between carbon and stem volume $\left(\mathrm{R}^{2}=92.7 \%\right)$.

$$
\sqrt{C_{s}}=17.8 \sqrt{v_{s}}
$$

where: $v_{s}=$ stem volume, $\mathrm{m}^{3}$ 


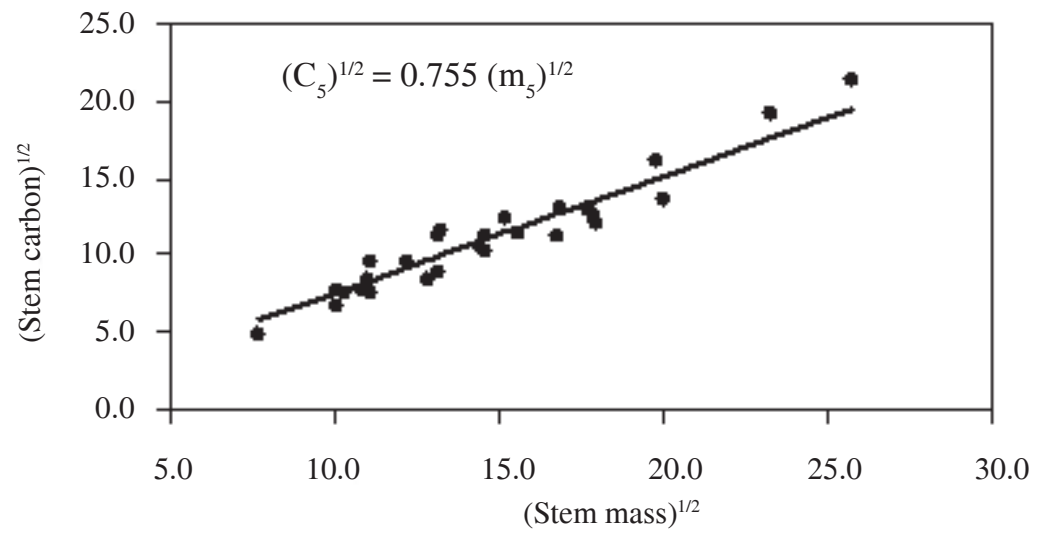

Figure 4: Observed stem carbon values and the fitted line for the selected model (7) to predict stem carbon $\left(\mathrm{C}_{\mathrm{s}}\right)$ from stem biomass $\left(\mathrm{m}_{\mathrm{s}}\right), \mathrm{R}^{2}=95.0 \%$

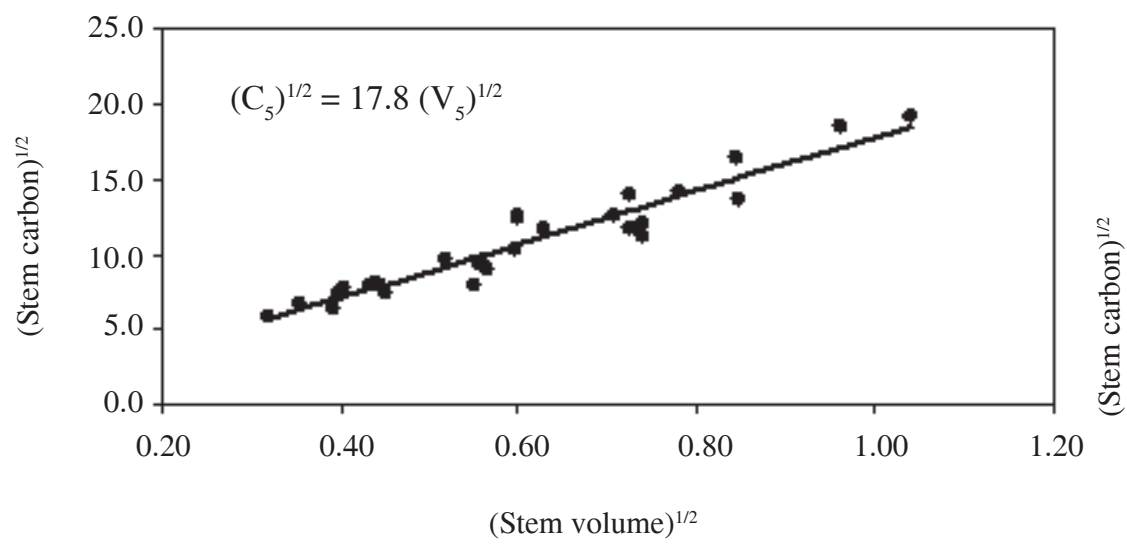

Figure 5:Observed stem carbon values and the fitted line for the selected model (8) to predict stem carbon (Cs) from stem volume (vs), R2 $=92.7 \%$

\subsubsection{Stem carbon vs diameter at breast height $(\mathrm{dbh})$}

For the relationships (7) and (8), the selected explanatory variables are practically difficult to measure. Therefore, in order to simplify the field work, it was decided to build a model to predict the stem carbon with easily measurable variables such as diameter and height.

Another twenty five models were initially identified for the relationship between stem carbon and diameter at breast height. $\sqrt{C_{s}}=-1.684+0.562 d$ was the best model among the initially selected 
ones. Its intercept was not significant $(p$ value $=0.068)$ and therefore the parameters were reestimated without the intercept to obtain model (9) which had the $\mathrm{R}^{2}$ of $89.4 \%$. Figure 6 illustrates the distribution of the fitted line of model (9).

$$
\sqrt{C_{s}}=0.492 d
$$

where: $d=$ tree diameter at breast height, $\mathrm{cm}$

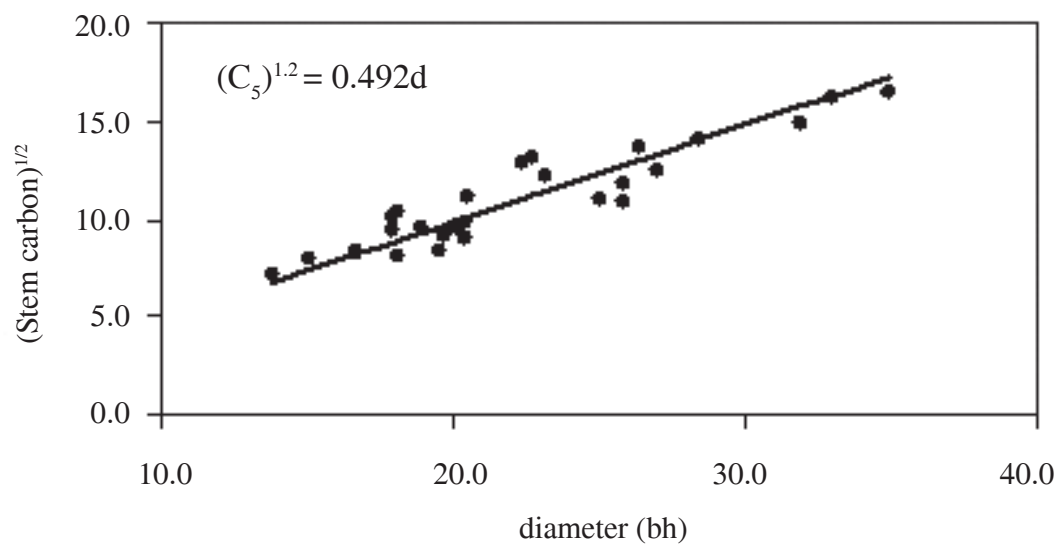

Figure 6: Observed stem carbon values and the fitted line for the selected model (9) to predict stem carbon $\left(\mathrm{C}_{\mathrm{s}}\right)$ from diameter at breast height $(\mathrm{d}), \mathrm{R}^{2}=89.4 \%$.

\subsubsection{Stem carbon vs dbh and total height}

The intention of adding total tree height as an additional explanatory variable was tested to identify the possibility of developing a more accurate model than model (9). The selected best model was $\sqrt{C_{s}}=8.93-223(1 / d)+2.72 \sqrt{h}$ which had a non-significant intercept ( $\mathrm{p}$ value $\left.=0.115\right)$. Model (10) shows the re-fitted model without the intercept. Its $\mathrm{R}^{2}$ value $(87.0 \%)$ was comparatively low though the standard residual distribution was reasonably good. Due to this reason, it was decided to recommend model (9) which uses only the dbh as the only explanatory variable for the field use.

$$
\sqrt{C_{s}}=-188(1 / d)+4.30 \sqrt{h}
$$

where: $h=$ total tree height, $\mathrm{m}$

\subsection{Construction of relationships to predict above ground tree carbon}

From the regression analyses carried out to build models to predict above ground tree carbon (carbon of stem, branches and leaves), the identified models are described below. 


\subsubsection{Above ground tree carbon vs above ground tree biomass}

From the initially developed twenty five models, the selected model (11) indicated a good fit (Figure 7) with a high $\mathrm{R}^{2}$ value of $97.7 \%$. Its original form was $\sqrt{C_{a g}}=0.624+0.744 \sqrt{m_{a g}}$ and the intercept was not significant $(\mathrm{p}$ value $=0.420$ ).

$$
\sqrt{C_{a g}}=0.777 \sqrt{m_{a g}}
$$

where: $C_{a g}=$ above ground tree carbon, $\mathrm{kg}$

$$
m_{a g}=\text { above ground biomass, } \mathrm{kg}
$$

The structure of this model was similar to that of the stem carbon prediction model from stem biomass model (7). However, the regression coefficient associated with $\sqrt{m_{a g}}$ for the model (11) is slightly higher than that of model (7).

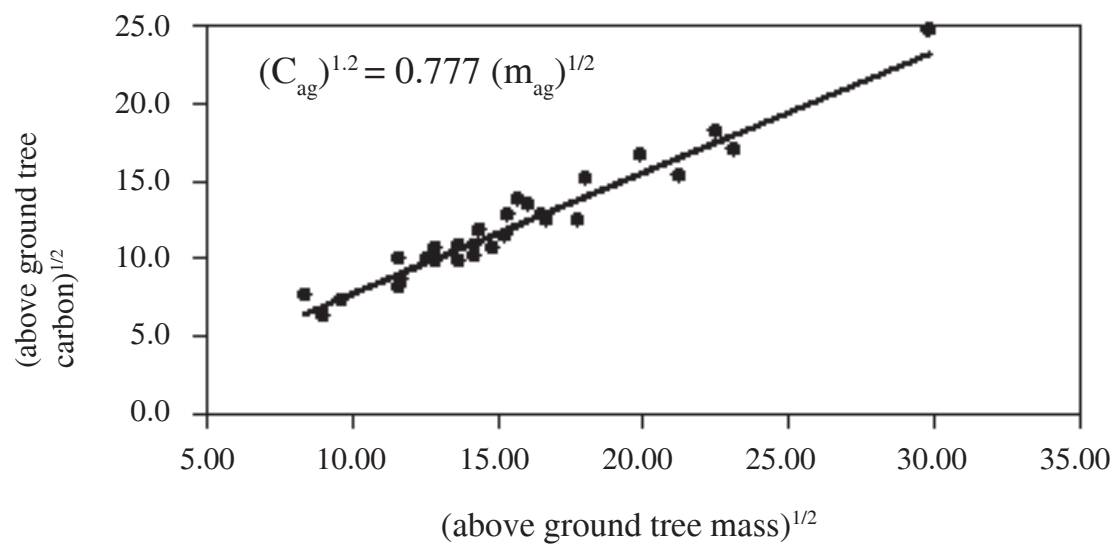

Figure 7: Observed above ground tree carbon values and the fitted line for the selected model (11) to predict above ground tree carbon $\left(\mathrm{C}_{\mathrm{ag}}\right)$ from above ground tree biomass $\left(\mathrm{m}_{\mathrm{ag}}\right), \mathrm{R}^{2}=97.7 \%$

\subsubsection{Above ground tree carbon vs stem volume}

Similar to the above procedures, above ground tree carbon was regressed against the stem volume and the selected model was given in equation (12). The best equation had non-transformed variables and the $\mathrm{R}^{2}$ of $96.0 \%$. Its standard residual distribution is given in Figure 8. Its original model was

$C_{a g}=9.08+352 v$ and the intercept was not significant $(\mathrm{p}$ value $=0.618)$. 


$$
C_{a g}=364 v
$$

where: $v=$ stem volume, $\mathrm{m}^{3}$

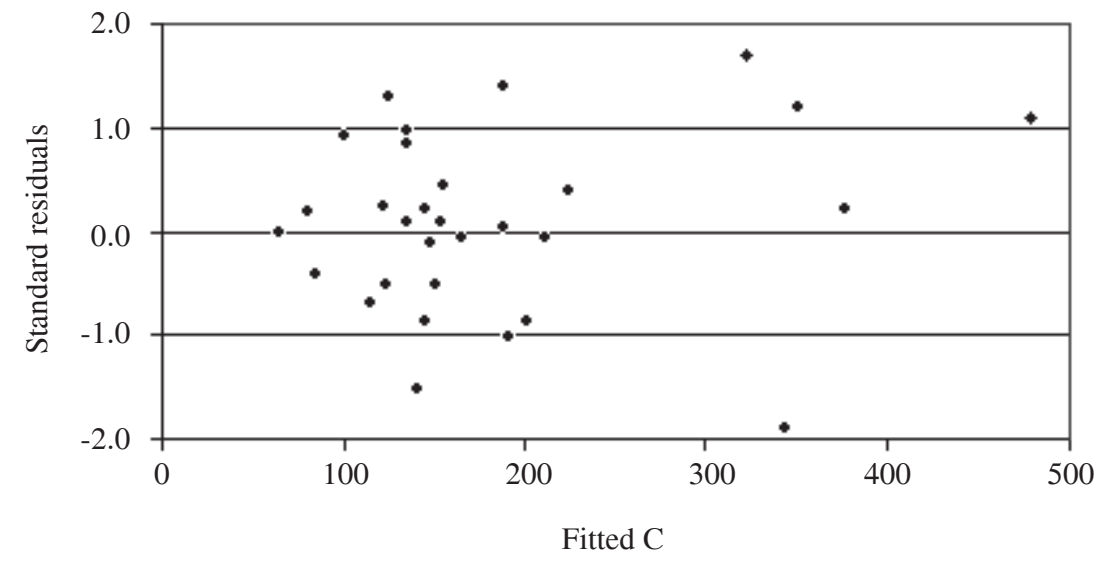

Figure 8: Standard residual distribution for model (12).

\subsubsection{Above ground tree carbon vs dbh}

Models (11) and (12) identify the relationship of above ground tree carbon of $P$. caribaea with above ground biomass stem volume. However, for the practical use, both models are impossible to use due to the difficulty of measuring the explanatory variables, i.e., tree mass and tree volume. Therefore, as a solution, another model was developed between above ground tree carbon and dbh which is easier to measure in the field. It (13) had $\mathrm{R}^{2}$ of $92.7 \%$ and also had a good standard residual distribution (Figure 10).

$$
C_{a g}=0.271 d^{2}
$$

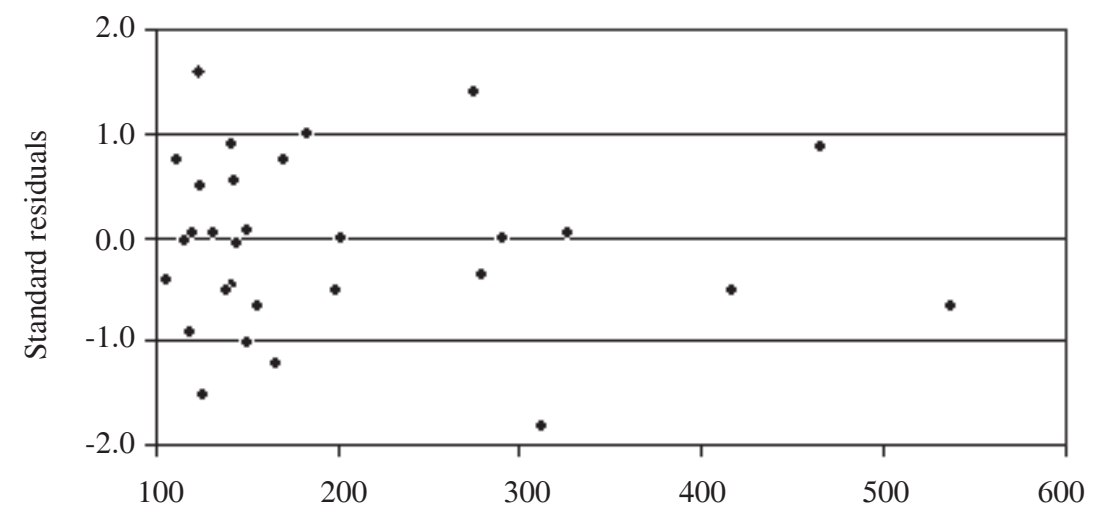

Figure 9: Standard residual distribution for model (13). 
The structure of the model 13 is different from the model developed to predict the stem carbon from dbh (model (10)). Although the explanatory variable (dbh), is included in non-transformed from for both models, the response variable stem carbon for the model (10) is in square root form and above ground carbon for the model (13) is in non-transformed form.

\section{Discussion}

Inventory data have often been used to estimate the biomass and carbon contents in tropical forests (Brown and Lugo, 1992) and in Europe (Kauppi et al., 1992). Most of such models were developed using dbh and height which are the common inventory data available in many countries (Segura and Kanninen, 2005). Considering the error that can be occurred by measuring various individual height terms, Segura and Kanninen (2005) recommended to develop models using dbh as the single explanatory variable to predict the tree carbon.

Emission of carbon dioxide and other green house gases are increasing due to human activities. The major carbon dioxide removing pathway from the lower atmosphere is the photosynthesis (leaves, branches, stem and roots) which store $\mathrm{CO}_{2}$ as carbohydrates. The stored $\mathrm{C}$ can be lost due to the leaf fall. However, Pinus is not a deciduous species and therefore the number of leaves in the canopy is maintained as a constant. Therefore, that loss is regained by the new leaves.

According to Dixon et al., (1994) the ration of total dry biomass to carbon is approximately 2:1. The $\mathrm{C}$ content of an undisturbed tropical moist forest has a high value, i.e., $250 \mathrm{~T} \mathrm{ha}^{-1}$ of standing above ground biomass. However, this study found that more than $50 \%$ from the biomass is carbon for $P$. caribaea. According to this study, the estimated above ground tree carbon content of the pine plantations in Sri Lanka is $103.63 \mathrm{~T} \mathrm{ha}^{-1}$. When compared with tropical forest storage of carbon, that amount is low in mature pine monocultures.

In 1983, Olsen et al., published average above ground stored carbon values per hectare by various vegetation communities. When compared the values obtained in this study with the above values for $P$. caribaea, the values estimated for this study is much higher. According to Schroeder (1991), the storage of above ground carbon was $59 \mathrm{~T} \mathrm{ha}^{-1}$ of Pinus caribaea within 15 year rotation age. The difference between the values obtained in this study his findings could be due to the difference of age and planting densities.

In this study, $\mathrm{C}$ prediction models were built from the selected explanatory variables to identify the pattern of relationships and best models for P. caribaea in Sri Lanka. In order to identify the best suitable models, the variables used were transformed into biologically acceptable forms i.e., square root, square, logarithmic and reciprocal following the work done by Subasinghe in 1998. The best models were selected depending on the $\mathrm{R}^{2}$ values and the standard residual distribution. The advantage of using the selected methodology for this study is that, it is not necessary to carry out the destructive sampling. Similar studies were conducted for forest biomass estimations in the past by Beets et al., (1999); Chhetri, (1999); Keller et al., (2001); Ketterings et al., (2001); Segura and Kanninen (2005).

This study had two main objectives, i.e., to identify the above ground biomass and carbon values for the selected species and to predict the above ground tree carbon from the tree variables which are not 
difficult to measure. By fulfilling the second objective, it was possible to recommend a method to estimate the above ground tree carbon for $P$. caribaea, so that the destructive sampling is not necessary in the future estimations. Ketterings et al., (2001) also proved that the destructive sampling is not necessary for biomass studies. Therefore the results of this study can be applied when estimating the ecosystem biomasses in large scale using the remotely sensed data.

\section{Conclusion}

Carbon storage of P. caribaea in Yagirala Forest Reserve is $103 \mathrm{MT} \mathrm{ha}^{-1}$ and for the whole country it is approximately $1,719,183 \mathrm{MT}$. This value was calculated assuming that all pine plantations contain the same number of trees per hectare and had similar growth rates.

It is possible to predict the amount of above ground carbon stored in the selected species using easily measurable variables such as diameter at breast height. Therefore complex and time-taking measurements are not needed in future for this purpose.

Limitation of the present study

Data collected from a single plantation was used in this study assuming that the age and the management treatments were similar for all P. caribaea plantations in Sri Lanka. However, it is a limitation in the present study and therefore it is recommended to validate the results with the data collected from several plantations in the future.

\section{References}

Bandaratillake, H.M., 2001. Administration report of the Conservator of Forests in Sri Lanka for the Year 2000. Forest Department, Sri Lanka

Beets, P.N., Robertson, K.A., Ford-Robertson, J.B., Gorden, J. and Maclaren, J.P., 2000. Description and validation of $\mathrm{C}$ change: a model for simulating carbon content in managed Pinus radiata stands. New Zealand Journal of Forestry Research 29 (3): 409-427

Brown, S. and Lugo, A.E., 1992. Above ground estimates for tropical moist forests of the Brazilian Amazon. Interciencia 17(1): 8-27

Chhetri, D.B.K., 1999. Comparison of forest biomass across a human-induced disturbance gradient in Nepal's Schima-Castanopsis forests. Journal of Sustainable Forestry 9(3-4): 69-82

Dixon, R.K., Brown, S., Hougton, R.A., Solomon, A.M., Trexler, M.S. and Wisniewski, J., 1994. Carbon pools and flux of global forest ecosystems, Science 263: 185-190

FAO, 2002. An international Journal of Forestry and Forest industry, FAO Forestry Paper 2002, Vol 53., Rome, Italy

Gunathilake, R.P.S.I.K. and Palambakumbura, S.C., 2001. Utility value of pine resource in Sri Lanka, Forest Department, Sri Lanka.

Haripriya, A.M.R., 2003. Relationship between individual stem volume and biomass for Pinus caribaea in the Yagirala Forest Reserve, Department of Forestry and Environmental Science, University of Sri Jayewardenepura, Sri Lanka 
Lugo, A.E. and Brown, S., 1992. Tropical forests as sinks of atmospheric carbon, Forest Ecoogy and Management 54: 239-255.

Kauupi, P.E., Mielikainen, K, and Kuusela, K., 1992. Biomass and carbon budget of European forests, 1971 to 1990. Science 256(5053): 70-74

Keller, M., Palace, M. and Hurtt, G., 2001. Biomass estimation in the Tapajos National Forest, Brazil. Examination of sampling and allometric uncertainties. Forest Ecology and Management 154 (3): 371-382

Ketterings, Q.M., Coe, R., Noordwijk, M. van., Ambagau, Y., Palm C.A. and van Noordwijk, M., 2001. Reducing uncertainty in the use of allometric biomass equations for predicting above-ground tree biomass in mixed secondary forests. Forest Ecology and Management 146 (1-3): 199-209

Kohlmaier, G.H., Weber, M. and Hougton, R.A., 1998. Carbon dioxide, mitigation in forestry and wood industry, Springer-Verleg, New York

Olsen, J.S., Watt, J.A. and Allison, L.J., 1983. Carbon in live vegetation of the major world ecosystems, US Department of Energy, Oak National Laboratory, Tennessee, USA

Philip, M.S., 1994. Measuring trees and forests, $2^{\text {nd }}$ ed. Cambridge University press, UK

Sedjo, R.A., Wisniewski, J, and Sampson, R.N., 1997. Economics of carbon sequestration in forestry, Lewis Publishers, Boca Raton

Segura, M. and Kanninen, M., 2005. Allometric models for tree volume and total above ground biomass in a tropical humid forest in Costa Rica. Biotropica 37(1): 2-8

Schroeder, P., 1991. Carbon storage potential of short rotation tropical tree plantations, EPA, Corvallis Region, USA

Subasinghe, S.M.C.U.P., 1998. Construction of growth models for Pinus nigra var. maritima (Ait.) Melville (Corsican pine) in Great Britain, Ph.D. Thesis, University of Wales Bangor, UK

William, M.C., 1995. Climatic change, Forest and Forest Management, FAO Forestry Paper No. 126, Food and Agricultural Organization, Rome 